\title{
Results of Preimplantation Genetic Testing for Aneuploidy (PGT-A) in a Cohort of 319 Embryos: Experience in a Fertility Clinic in Colombia
}

\author{
Germán David Ospina Idárraga ${ }^{1}$, Iván Darío Montes Suárez ${ }^{1,2}$, Katherine Gisell Hernández Osorio1, Diana Milena \\ Diaz Corredor ${ }^{1,3}$, Johanna Carolina Páez Redondo ${ }^{1}$, Ricardo Garcia Yepes ${ }^{4}$
}

${ }^{1}$ Instituto de Fertilidad Humana - Inser Bogotá, Colombia

${ }^{2}$ Clínica del Country - Bogotá, Colombia

3Master in Epidemiology Universidad del Rosario, Bogotá, Colombia

¿Universidad del Rosario, Bogotá, Colombia

\begin{abstract}
Objective: To analyze the results of the preimplantation genetic testing for aneuploidy at the Instituto de Fertilidad Humana - Inser Bogotá, Colombia, from 2016 to 2020.

Methods: This study is an observational, retrospective, and correlative analysis of biopsies from 319 embryos (from 54 patients) submitted to preimplantation genetic testing for aneuploidy by different molecular techniques.

Results: Of the 54 patients included in the study, 42 provided their own oocytes, and 12 used donated oocytes. The main indication to perform the preimplantation genetic testing was advanced maternal age. We obtained 319 embryos: Ninety-one (28.5\%) euploid, 197 (61.8\%) aneuploid and $31(9.7 \%)$ with no detectable DNA. The highest rate of aneuploid embryos was found in patients over 40 years $(72.7 \%)$, and the euploidy rate in patients under 35 years was $37.1 \%$. After the transfer of euploid embryos, the rates for implantation, ongoing pregnancy, live birth, and miscarriage were $40 \%, 50 \%, 40.6 \%$, and $0 \%$, respectively. Older maternal age correlated with higher numbers of aneuploid embryos and lower numbers of both euploid and 5-day embryos.

Conclusions: There was a positive correlation between maternal age and aneuploidy rate. Complex chromosomal abnormalities were the most frequent aneuploidies, followed by mosaicism and double aneuploidies. The miscarriage rate after the transfer of euploid embryos was $0 \%$.
\end{abstract}

Keywords: aneuploidy, preimplantation genetic testing, biopsy, embryo

\section{INTRODUCTION}

One of the leading causes of Assisted Reproduction Techniques (ART) failure is the transfer of aneuploid embryos (Wilton, 2002). Maternal age is a decisive factor in the generation of chromosomal alterations in the embryo; so that by the age of 35 , the aneuploid embryo rate is significantly lower than in women over 40 years. After in vitro fertilization (IVF), the pregnancy rate is $31 \%$ in women under 35 years and just $10.2 \%$ in women over 40 years (Revelli et al., 2016). Embryo chromosomal abnormalities are more common in women of advanced reproductive age (ARA) (Franasiak et al., 2014; Harton et al., 2013; Milán et al., 2010; Schoolcraft et al., 2009); recurrent pregnancy loss (RPL) (Hodes-Wertz et al., 2012; Vitez et al., 2019); recurrent implantation failure (RIF) (Greco et al., 2014; Rubio et al., 2013a); severe male factor (SMF) (Practice Committees of the American Society for Reproductive Medicine \& the Society for Assisted Reproductive Technology, 2018; Magli et al., 2009); and history of aneuploidies in the offspring (Harper et al., 2010).
The morphological classification of embryos has been the most widely used method in IVF techniques to evaluate and stage embryo quality (Ebner et al., 2003). This method is limited to assessing morphological characteristics that are not necessarily related to euploidy (Ebner et al., 2003). The evolution of ART and the advances of molecular biology have enabled the development of new techniques to analyze the number of chromosomes and establish the embryo ploidy, optimizing the transfer of chromosomally healthy embryos (Ebner et al., 2003; Harper et al., 2010). Several molecular techniques have been used in recent years to determine the embryo's genetic quality, including Fluorescent In Situ Hybridization (FISH) (Álvarez Sedó, 2018; Wilton, 2002), Array Comparative Genomic Hybridization (aCGH) (Ata et al., 2012; Rubio et al., 2013b; Rodrigo et al., 2014), quantitative real-time PCR (qPCR), Single Nucleotide Polymorphisms (SNP), and Next Generation Sequencing (NGS) (Fiorentino et al., 2014; Kung et al., 2015; Palmerola et al., 2019). The aCGH analyzes the entire genome with a high resolution; it is a powerful, agile, and highly specific tool suitable to diagnose chromosome gains; however, it cannot detect point mutations or balanced rearrangements (Shinawi \& Cheung, 2008). The NGS enables the simultaneous screening of millions of DNA or RNA sequences and performs several analyses simultaneously in the same embryo (monogenic disorders, structural alterations, and aneuploidies). This technique has better accuracy, high performance and sensibility to detect genetic variants of low frequency (Zhong et al., 2021).

These molecular techniques require an embryo biopsy obtained at different developmental stages (Harper et al., 2010). According to results from randomized controlled trials, the 2012 European Preimplantation Genetic Diagnosis (PGD) Consortium advised against taking biopsies from blastomeres and against the use of the FISH technique; likewise, it recommended the trophectoderm biopsy and the chromosomal material analysis by NGS (Harper et al., 2010).

At the PGD European Consortium, preimplantation genetic testing for aneuploidy (PGT-A) was reported for 6,095 cycles of IVF. The test was indicated in cases of ARA $(40 \%)$, $\operatorname{RIF}(12 \%), A R A$ and RIF (12\%), ARA and RPL (10\%), and SMF $(10 \%)$. Other indications were previous abnormal pregnancies, impaired paternal or maternal karyotype including mosaicisms; a small number of couples did not have a medical indication (Harper et al., 2012).

Since 1990, pregnancies resulting from the transfer of IVF-embryos previously tested by molecular techniques have been documented and accounted for approximately 11,000 live births by 2010 (Simpson, 2010). However, there are controversial reports; some of them support (Chen et al., 2015; Coates et al., 2017; Rubio et al., 2013a; Scott et al., 2013; Wilton, 2002; Yang et al., 2012) but 
others discourage (Chang et al., 2016; Kang et al., 2016; Mastenbroek et al., 2011) the use of PGT-A as a strategy to increase both implantation and live birth rates. This study aimed to analyze the PGT-A results reported at the Instituto de Fertilidad Humana - Inser Bogotá, Colombia.

\section{MATERIALS AND METHODS}

This study was an observational, retrospective and correlative analysis of the PGT-A results of embryo biopsies collected between February 2016 and March 2020 at the Instituto de Fertilidad Humana - Inser Bogotá, Colombia.

The study was approved by the Medical and Research Ethics Committee of the Instituto de Fertilidad Humana Inser Bogotá, ensuring the study's compliance vis-à-vis the ethical standards and those defined in the $1975 \mathrm{Hel}-$ sinki declaration, revised in 2013. All patients filled out and signed an institutional and reference laboratory informed consent form, accepting the procedures, risks and possible complications. Fifty-four patients gave their consent for 319 biopsies to be taken.

\section{Ovarian hyperstimulation, fertilization, and em- bryo culture \\ Controlled ovarian hyperstimulation $(\mathrm{COH})$ was per-} formed under a flexible Gonadotropin-releasing hormone antagonist $(\mathrm{GnRH})$ protocol. Gonadotropin doses were adjusted according to age, body mass index, and ovarian reserve testing. The oocytes retrieved through follicular aspiration were cultured in Life Global Total medium/ HEPES (Life Global ${ }^{\circledR}$ ) or GMops Plus (Vitrolife ${ }^{\circledR}$ ) for two hours until decumulation using ICSIcumulase (Origio ${ }^{\circledR}$ ) or Hyase (Vitrolife ${ }^{\circledR}$ ). Subsequently, the ICSI was conducted, and the injected oocytes were cultured in NUNC ${ }^{\mathrm{TM}}$ plates (CN 150255 Nunc $^{\circledR}$ ) in Life Global Total or GTL plus (Vitrolife ${ }^{\circledR}$ ) culture medium under a mineral oil layer (LiteOil; Life Global ${ }^{\circledR}$ or OVOIL; Vitrolife ${ }^{\circledR}$ ), and incubated at a pH of 7.3, $5 \%$ oxygen and $8,9 \% \mathrm{CO} 2$ in Tri-Gas incubators (K-Systems ${ }^{\circledR}$ ). Until August 2018, Life Global ${ }^{\circledR}$ media were used; but since then, and following changes in the laboratory's internal protocols, Vitrolife ${ }^{\circledR}$ media is being used.

After ICSI, fertilization was assessed between 16 and 18 hours; embryo culture continued for 72,120 or 144 hours according to the embryo development. The 72-hour embryos were classified according to their blastomere number and fragmentation percentage (ASEBIR, 2015), while 120- and 144-hour embryos were graded according to the Gardner and Schoolcraft's system (Gardner et al., 1998).

\section{Embryo biopsy}

The 72-hour embryos were selected only if they had between 7 and 10 blastomeres and a fragmentation lower than $15 \%$. These embryos were cultured in NUNC ${ }^{\mathrm{TM}}$ plates (CN 150265; Nunc) using Life Global PGD Biopsy Medium (Life Global ${ }^{\circledR}$ ) and under a mineral oil layer (LiteOil or OVOIL). The embryo was held using a holding pipette (Origio ${ }^{\circledR}$ or $\mathrm{RI}^{\circledR}$ ) on an inverted microscope equipped with a micromanipulation system. A mononuclear blastomere was chosen, and its zona pellucida was laser-drilled (Lykos ${ }^{\circledR}$; Hamilton Thorne, USA) before aspiration, using a biopsy pipette (Origio ${ }^{\circledR}$ ). The retrieved cell was cultured into Life Global Total/HEPES medium or in GMops Plus.

Since July 2017, modifications to InSer's internal protocols established that trophectoderm biopsies be held at 120 and 144 hours for all the embryos to be analyzed by PGT-A. For this reason, the embryos were cultured on NUNC ${ }^{\mathrm{TM}}$ plates (CN 150265; Nunc) with Life Global Total medium/HEPES or GMops Plus under a mineral oil layer (LiteOil or OVOIL;). Before the biopsy (12 to 24 hours), the zona pellucida was laser-pierced (Lykos- ${ }^{\circledR}$; Hamilton
Thorne). Then, using an inverted microscope equipped with a micromanipulation system, the blastocysts were fixed by a holding pipette, and 6 to 10 cells were aspirated with a microinjector and the biopsy pipette. The cells were then severed by 3 to 4 diode laser shots at 500 pulses per microsecond or flicking. The cells obtained in the biopsy were released into Life Global Total/HEPES medium or GMops Plus.

For tubing (cell isolation), the aspirated trophectoderm cells were washed with sterile phosphate-buffered saline solution and transferred to sterile microtubes containing an isolation medium for molecular testing. A total of 319 embryo biopsies were split to be sent to different laboratories for chromosomal analysis as follows: 136 biopsies to Igenomix Laboratories in the United States of America (76 for NGS and 60 for aCGH), 142 to Sistemas Genómicos in Spain (for NGS), and 28 and 13 respectively to Colgenes and Genetix in Colombia to be analyzed by NGS.

The laboratories used to classify these chromosomal abnormalities as numerical and segmental according to internal criteria. It is important to note that the chromosomal abnormalities mostly reported are monosomy, trisomy, deletion or duplication, and mosaicism. These alterations can be combined, and depending on the number, they are called double, complex, and chaotic. For this study, the combined abnormalities were classified as double (two numerical or segmental alterations), complex (three to four abnormalities), and chaotic (five or more alterations).

\section{Vitrification and thawing}

Vitrification was performed using the Cryotech ${ }^{\circledR}$ kit following the manufacturer s protocols. All the embryos were vitrified immediately after performing the biopsy. The Euploid embryos were thawed using the Cryotech ${ }^{\circledR}$ kit and cultured in Life Global Total or GTL plus medium between 4 and 6 hours before their transfer. On the other hand, the embryos that were biopsied at 72 hours of development were further cultured until the blastocyst stage for transfer purposes.

\section{Embryo transfer and pregnancy confirmation}

Before embryo transfer, the recipient women were subjected to an endometrial preparation protocol with $\mathrm{GnRH}$ agonists and oral estrogens (progressive doses until reaching 6 to $8 \mathrm{mg} /$ day of Progynova, Bayer $\left.^{\circledR}\right)$. When the expected endometrial thickness was achieved, treatment with progesterone (600 to $800 \mathrm{mg} /$ day) was initiated. On the $5^{\text {th }}$ day of progesterone administration, one or two embryos were transferred through the cervical canal into the uterine cavity using a $\mathrm{Cook}^{\circledR}$ transfer catheter under transabdominal ultrasound guidance.

The pregnancy test was performed 14 days after embryo transfer by quantitative determination of Human Chorionic Gonadotropin beta subunit (b-HCG) in the serum. Ultrasound monitoring was carried out at six weeks of pregnancy, and prenatal care was continued in the positive cases.

\section{Data Analysis}

This study analyzed data from women who underwent PGT-A at the Instituto de Fertilidad Humana- InSer, Bogotá between February 2016 and March 2020. The analyses were performed in a total of 319 embryos. Their medical records were reviewed, and the following variables were analyzed: patient age, indication for PGT-A, oocyte origin, total gonadotropin dose administered, the total number of mature and immature oocytes collected, total number of 72-, 120-, and 144- hour embryos, number of biopsied embryos, PGT-A results, molecular technique used for PGT-A, number of transfers, number of embryos transferred, number of patients who received embryos, 
pregnancy test result, number of gestational sacs visualized, and number of live births.

Statistical analyses were run in the SPSS v22.0 software. We ran a descriptive analysis using absolute and relative frequencies for qualitative variables, and mean and standard deviation (SD), or median and interquartile range (IQR) for qualitative variables, depending on data distribution. The normality of variable distribution was analyzed by the Shapiro-Wilk and Kolmogorov- Smirnov tests. The correlations between variables were determined by the Pearson or Spearman correlation coefficients, with a statistically significant $p$-value $<0.05$; according to the coefficient calculated, the correlation was interpreted as very low (0.00-0.19); low (0.20-0.39), moderate (0.40-0.59), good (0.60-0.79), and very good (0.80-1.00).

Additionally, the rates for implantation, ongoing pregnancy per transferred patients, live birth per transferred patients, and miscarriage were calculated according to the following formulas:

Implantation rate $=$ (number of gestational sacs observed/number of transferred embryos) X 100 .

Ongoing pregnancy rate per transferred patients $=$ (number of patients with at least one gestational sac after week 5 with fetal heartbeat/ number of transferred patients) $\times 100$.

Live birth rate per transferred patients $=$ (number of births resulting in at least one live birth/number of transferred patients) $\times 100$.

Miscarriage rate $=$ (number of patients with pregnancy loss by week $12 /$ (number of patients presenting at least one gestational sac after week 5) X 100.

\section{RESULTS}

The study included 54 women: 42 patients (median age 40 years; IQR $=37-42$ ) provided their own oocytes, and 12 (median age 24.5 years; IQR $=22.2-26.7$ ) used donated oocytes. All oocytes provided accounted for a total of 319 embryos (Table 1 ).

The analysis found that the main indications for PGT-A were ARA, the combination of 2 or 3 indications, and screening, followed by RIF and RPL as unique indications (Table 2). In the group of 42 patients who provided their own oocytes (some required up to $3 \mathrm{COH}$ cycles), the number of oocytes collected reached a median of 14.5 (IQR = 9-24.2): 11 (IQR = 7-17) oocytes at metaphase II and 3.5 $(\mathrm{IQR}=1.75-6.25)$ immature oocytes.

A total of 319 embryos were produced in vitro with a median of 5 (IQR = 2.7-7.2) embryos per patient. Of these embryos, 91 were euploid, 197 aneuploid, and 31 could not be classified because DNA was not detected in the samples (Table 3).

The chromosomal alterations identified were mainly complex anomalies followed by mosaicism and double aneuploidies (Table 4). Monosomies were mainly located

Table 1. Distribution of patients by age.

\begin{tabular}{|l|c|}
\hline $\begin{array}{l}\text { Age range } \\
\text { (years) }\end{array}$ & Number of patients (\%) \\
\hline$<35$ & $15(27.8)^{*}$ \\
\hline $35-37$ & $10(18.5)$ \\
\hline $38-40$ & $11(20.4)$ \\
\hline$>40$ & $18(33.3)$ \\
\hline Total & 54 \\
\hline
\end{tabular}

* Including 12 women who were given embryos produced from donated oocytes on chromosomes 15,16 , and 18 , and trisomy in chromosomes 15,21 and 22 .

Most biopsied embryos came from women under 35 years of age and exhibited the highest euploidy rate. In contrast, the highest rate of aneuploid embryos was found in patients over 40 years of age (Table 5 ).

Biopsies taken from 60 embryos $(18.8 \%)$ were analyzed by aCGH; this group consisted of embryos cultured for different hours as follows: $72-h(n=37), 120-h(n=21)$, and 144-h $(n=2)$. The abnormalities most frequently observed were complex aneuploidies followed by segmental aneuploidies and monosomies (Tables 6 and 7). Seven of these 60 embryos were transferred to 6 patients, and two positive pregnancy tests were detected afterwards.

On the other hand, biopsies taken from 259 (81.2\%) embryos were analyzed by NGS; this group also contained embryos cultured for different hours: $72-h(n=9), 120-h$ $(n=194)$ and $144-h(n=56)$. The most common anomalies found were complex aneuploidies followed by mosaicism and double alterations; a lower number of segmental alterations were detected. The percentage of embryos with undetectable DNA was similar in both molecular techniques (Tables 6 and 7). The transfer of 38 of these 259 embryos to 26 patients resulted in 15 positive pregnancy tests.

Forty-five of the 91 euploid embryos obtained were used in 33 transfers to 32 patients with a resulting median for embryo transfer of 1 (IQR $=1-2) ; 19(59.3 \%)$ patients underwent single embryo transfer (SET) and 13 (40.6\%) received two embryos. Afterwards, there were 17 positive pregnancy tests. Forty-six euploid embryos have not yet been transferred and are kept vitrified.

Rates for implantation, clinical pregnancy, live birth, and miscarriage were calculated in this study (Table 8). Besides, the implantation rates according to the molecular technique were $14.2 \%$ and $44.7 \%$ for aCGH and NGS, respectively.

Correlation analysis between age and other variables showed that the older the patient, the greater the number of aneuploid embryos (low positive correlation), the lower the numbers of 120-hou embryos (good negative correlation), the lower the euploid embryos (moderate negative correlation) (Table 9).

\section{DISCUSSION}

Throughout the history of reproductive medicine, many ART-optimizing techniques have been introduced. Among them, IVF, ICSI, vitrification, and PGT-A approaches are worth mentioning (Álvarez Sedó, 2018). Since its introduction, the PGT-A has emerged as a tool to improve pregnancy rates compared to other approaches, where no embryo genetic testing was performed.

A well-known feature of the human species is the increased generation of aneuploid embryos as the maternal age advances; this characteristic gives rise to lower implantation and pregnancy rates, increased miscarriages and chromosomal diseases (Ata et al., 2012; Harton et al., 2013). The main objective of PGT-A is the selection of euploid embryos, intended to increase the live birth rate by promoting the SET and reducing the time to achieve a successful pregnancy (Álvarez Sedó, 2018). However, the initial results that seemed to be promising to have gradually lost their applicability due to controversial reports in different recent publications.

The present study showed increased aneuploidy rates in embryos from older women: $72.7 \%$ of aneuploid embryos were identified in patients over 40 years of age. There is similar data in the literature, e.g., the study by Harton et al. (2013) reported that in women over 40 years, the aneuploidy rates in embryos biopsied on days 3 and 5 were $85.8 \%$ and $76.3 \%$, respectively. Another study of 


\begin{tabular}{|l|c|c|}
\hline \multicolumn{2}{|l|}{ Table 2. Distribution of patients by PGT-A indication. } & Percentage (\%) \\
\hline Indication for PGT-A & Number of patients & 28.9 \\
\hline ARA & 14 & 25.9 \\
\hline Combination of 2 or 3 indications * & 13 & 5.6 \\
\hline Screening & 3 & 3.7 \\
\hline RIF & 2 & 1.8 \\
\hline RPL & 1 & 100 \\
\hline $\begin{array}{l}\text { Family history of aneuploid } \\
\text { pregnancies }+\end{array}$ & 54 & \\
\hline Total & 21 & \\
\hline
\end{tabular}

*Combinations found: ARA/RPL: 4; ARA/RIF: 1; ARA/personal or family history: 1; RIF/RPL: 1; screening/personal or family history: 3 ; RIF/personal or family history: 1 ; RPL/personal or family history: 1 ; ARA/RIF/RPL: 1 ; ARA/RPL/ personal or family history: 1.

+ Family history of aneuploid pregnancies: patient with a second degree relative with Down syndrome.

\begin{tabular}{|l|c|c|}
\hline Table 3. PGT-A results. & \multicolumn{2}{|c|}{ Frequency (\%) } \\
\hline PGT-A result & Number of cases & 28.5 \\
\hline Euploid Embryos & 91 & 61.8 \\
\hline Abnormal Embryos & 197 & 9.7 \\
\hline Undetected DNA & 31 & 100 \\
\hline Total & 319 & \\
\hline
\end{tabular}

\begin{tabular}{|l|c|c|}
\hline Table 4. Aneuploidies reported in abnormal embryos. & Frequency (\%) \\
\hline Aneuploidy & Number of cases & 15.2 \\
\hline Monosomies & 30 & 12.2 \\
\hline Trisomy & 24 & 15.2 \\
\hline Double aneuploidy & 30 & 9.6 \\
\hline Deletion or Duplication & 19 & 18.3 \\
\hline Mosaicism & 36 & 26.4 \\
\hline Complex aneuploidy & 52 & 3.1 \\
\hline Chaotic aneuploidy & 6 & 100 \\
\hline Total & 197 & \\
\hline
\end{tabular}

\begin{tabular}{|c|c|c|c|c|c|c|c|}
\hline \multirow{3}{*}{$\begin{array}{l}\text { Women age } \\
\text { (years) }\end{array}$} & \multicolumn{7}{|c|}{ Embryos screened by PGT-A } \\
\hline & \multirow{2}{*}{$\frac{\text { Total }}{\text { (n) }}$} & \multicolumn{2}{|c|}{ Euploid } & \multicolumn{2}{|c|}{ Aneuploid } & \multicolumn{2}{|c|}{ Undetectable DNA } \\
\hline & & (n) & $(\%)$ & (n) & $(\%)$ & (n) & $(\%)$ \\
\hline$<35$ & 105 & 39 & 37.1 & 58 & 55.2 & 8 & 7.7 \\
\hline $35-37$ & 88 & 27 & 30.7 & 50 & 56.8 & 11 & 12.5 \\
\hline $38-40$ & 60 & 14 & 23.3 & 41 & 68.4 & 5 & 8.3 \\
\hline$>40$ & 66 & 11 & 16.7 & 48 & 72.7 & 7 & 10.6 \\
\hline
\end{tabular}

15,169 embryos found aneuploidy rates of $58 \%$ among patients older than 40 years and a steadily increasing rate up to approximately $85 \%$ in 43 -year-old patients (Franasiak et al. 2014).

The genetic abnormalities mainly identified in aneuploid embryos were double, complex, and numerical in patients over 38 years of age; and segmental in those under 35 years. As shown by some studies, numerical aneuploidies increase with age while segmental or single chromosome alterations decrease (Franasiak et al., 2014; Sánchez-Usabiaga et al., 2017). Moreover, complex abnormalities progressively increase with age, as reported in the study by Rodrigo et al. (2014), where two groups of embryos were analyzed; the first group included 3,146 embryos, from women under 40 years, in which $14.2 \%$ of chaotic aneuploidies and $20.8 \%$ of double and complex aneuploidies were detected; in the second group, 3,972 embryos from women over 40 
Table 6. PGT-A results according to the molecular technique.

\begin{tabular}{|l|c|c|c|c|}
\hline \multirow{2}{*}{ PGT-A result } & \multicolumn{5}{|c|}{ Molecular technique } \\
\cline { 2 - 5 } & \multicolumn{2}{|c|}{ aCGH } & \multicolumn{3}{c|}{ NGS } \\
\cline { 2 - 5 } & (n) & \% & 79 & 30.5 \\
\hline Normal embryos & 12 & 20 & 155 & 59.8 \\
\hline Abnormal embryos & 42 & 70 & 25 & 9.7 \\
\hline Undetected DNA & 6 & 10 & 259 & 100 \\
\hline Total & 60 & 100 & & 79 \\
\hline
\end{tabular}

Table 7. Aneuploidies found in embryos according to the molecular technique.

\begin{tabular}{|c|c|c|c|c|}
\hline \multirow{3}{*}{ PGT-A result } & \multicolumn{4}{|c|}{ Molecular technique } \\
\hline & \multicolumn{2}{|c|}{ aCGH } & \multicolumn{2}{|c|}{ NGS } \\
\hline & (n) & $\%$ & (n) & $\%$ \\
\hline Monosomies & 8 & 19.0 & 22 & 14.2 \\
\hline Trisomy & 4 & 9.5 & 20 & 12.9 \\
\hline Double aneuploidy & 6 & 14.3 & 24 & 15.5 \\
\hline Deletion or duplication & 11 & 26.2 & 8 & 5.2 \\
\hline Mosaicism & 0 & 0 & 36 & 23.2 \\
\hline Complex Aneuploidy & 12 & 28.6 & 40 & 25.8 \\
\hline Chaotic Aneuploidy & 1 & 2.4 & 5 & 3.2 \\
\hline Total & 42 & 100 & 155 & 100 \\
\hline
\end{tabular}

Table 8. Implantation, clinical pregnancy, live birth and miscarriage rates.

\begin{tabular}{|l|c|}
\hline Estimated rate & Overall Result \\
\hline Implantation rate & $40.0 \%$ \\
\hline Ongoing pregnancy rate & $50.0 \%$ \\
\hline Live birth rate & $40.6 \%$ \\
\hline Miscarriage rate & $0.0 \%$ \\
\hline
\end{tabular}

years of age exhibited $15.6 \%$ of chaotic aneuploidies and $43.1 \%$ of double and complex aneuploidies.

In the current study, the main indication for PGT-A was the advanced maternal age (46.4\%). In this group of patients, it is essential to identify and select healthy embryos to be transferred to increase implantation and decrease the miscarriage rates. Older women not only have a higher risk of producing aneuploid embryos, but also a lower number of embryos owing to their low ovarian reserve and oocyte quality; all these factors affect embryo development, making it difficult to obtain blastocysts suitable for PGT-A (Harton et al., 2013). As an alternative, some patients choose to undergo treatment using donated oocytes; nevertheless, some studies advise against the use of PGT-A in these cases due to the lack of significant differences in pregnancy and miscarriage rates when comparing embryos (produced from donated oocytes) screened or not by PGT-A (Haddad et al., 2015).

In patients with RIF, PGT-A increases the chance of pregnancy by the transfer of euploid embryos (Forman et al., 2013; Greco et al., 2014; Rubio et al., 2013a). Howev$\mathrm{er}$, it is important to note that other factors (endometrial receptivity, inadequate expression of endometrial adhesive molecules, autoimmune diseases and uterine physiological alterations) can affect the embryo's ability to develop, hatch and implant and, consequently, hinder the growth of even euploid embryos (Achache \& Revel, 2006). This issue was supported by a study of patients with RIF by Blockeel et al. (2008) who did not find significant differences in pregnancy rates after transferring them with embryos tested or not by PGT-A. In the present study, in patients with RIF, the aneuploidy rate was $62.5 \%$; and the pregnancy test was positive in $71.4 \%$ of cases after transfer of euploid embryos.

One of the main causes of RPL is the presence of aneuploid embryos; in this study, RPL was an indication for using PGT-A in $18.5 \%$ of patients. Several studies have demonstrated a decrease in the miscarriage rate when PGT-A is performed (Hodes-Wertz et al., 2012; Simon et al. , 2018). Furthermore, in couples suffering from RPL with a history of genetic abnormalities, PGT (PGT-A, PGT-M, PGT-SR) is an option for aneuploidy screening, monogenic diseases and structural and numerical chromosomal abnormalities; it avoids the transfer of abnormal embryos and the consequent risk of miscarriage (ESHRE, 2017). In this study, most patients had an indication to request a genetic study and only $24.1 \%$ of them requested a PGT-A for screening purposes, which explains the high rate of aneuploidy here reported.

In the current study, the implantation rate was $40 \%$ after the transfer of euploid embryos; similar figures were published in cases not screened by PGT-A by the REDLARA (Red Latinoamericana de reproducción asistida) in 2017. It reported implantation rates of $37.8 \%$ after transfer of own-thawed embryos, and $43.7 \%$ for embryos produced from donated oocytes (Zegers-Hochschild et al., 2020a;b). Notwithstanding, other studies support the relevance of PGT-A in the improvement of embryo implantation; for instance, a study found implantation rates of $63.2 \%$ in patients who were given euploid embryos and of $51.2 \%$ in those who received two blastocysts without PGT-A (Forman et al., 2013). Another study published implantation 


\begin{tabular}{|l|l|c|c|}
\hline Table 9. Correlation Analysis. & Rho Spearman & \multicolumn{1}{|c|}{-value } \\
\hline \hline \multirow{4}{*}{ Dependent variable } & Independent variables & 0.227 & 0.15 \\
\hline \multirow{5}{*}{ Age } & Total gonadotropin dose & -0.261 & 0.09 \\
\cline { 2 - 4 } & Total number of oocytes retrieved & -0.308 & $\mathbf{0 . 0 4 7}$ \\
\cline { 2 - 4 } & Total number of oocytes, metaphase II & 0.147 & $\mathbf{0 . 3 4 8}$ \\
\cline { 2 - 4 } & Total number of 3-day embryo & -0.677 & $\mathbf{0 . 0 0 0}$ \\
\cline { 2 - 4 } & Total number of 5-day embryo & 0.175 & 0.206 \\
\cline { 2 - 4 } & Total number of 6-day embryo & -0.439 & $\mathbf{0 . 0 0 1}$ \\
\cline { 2 - 4 } & Total vitrification & -0.535 & $\mathbf{0 . 0 0 0}$ \\
\cline { 2 - 4 } & Number of embryos/patient & -0.440 & $\mathbf{0 . 0 0 1}$ \\
\cline { 2 - 4 } & \% normal embryos & 0.385 & $\mathbf{0 . 0 0 4}$ \\
\cline { 2 - 4 } & $\%$ abnormal embryos & & \\
\hline
\end{tabular}

rates of $66.4 \%$ and $47.9 \%$ after the transfer of embryos with or without PGT-A screening, respectively (Scott et al., 2013).

In the present study, the implantation rate was higher when the PGT-A was performed by NGS than by aCGH. This difference may be attributed to the higher efficiency of NGS and the timing of the introduction of aCGH at InSer, which coincided with implementing the genetic testing analysis program; therefore, some factors such as skill and expertise could have affected the results.

According to the study by Homer (2019), the live birth rate in cases with PGT-A does not vary significantly since the embryo potential is not increased by the PGT-A itself; however, miscarriage rates may be reduced by performing the PGT-A For instance, the study by Yang et al. (2012) found clinical pregnancy rates of $70.9 \%$ in cases of embryos graded by morphology and screened for chromosomal anomalies by aCGH, and $45.8 \%$ in cases of embryos selected only by morphological criteria. In a similar study, clinical pregnancy rates were $52.1 \%$ and $34.9 \%$ when embryos had been screened respectively by PGT-A or morphology on day five (Rubio et al., 2013a). In the present study, the ongoing pregnancy rate in cases with PGT-A was $50 \%$, a figure consistent with data from other studies reporting significant improvement in ongoing pregnancy rates when PGT-A was performed (Ata et al., 2012; Chen et al., 2015; Coates et al., 2017; Harper et al., 2012; Hodes-Wertz et al., 2012; Munné et al., 2016).

The miscarriage rates reported by the REDLARA in 2017 when PGT-A had been performed were 12.8\%, $13.9 \%$, and $9.3 \%$ in women under 35 years, between 35 and 39, and over 39 years, respectively; in contrast, in cases without the PGT-A screening, the figures for the same age groups were $15.3 \%, 17.8 \%$, and $23.7 \%$, respectively (Zegers-Hochschild et al., 2020a;b). In the present study, the miscarriage rate upon PGT-A was $0 \%$, but this figure could have been minimized due to the limited number of patients analyzed. Notwithstanding, the PGT-A could be a useful tool to reduce the time to pregnancy for patients with RPL. As the literature shows, several studies described that PGT-A considerably reduces the miscarriage rate (Practice Committees of the American Society for Reproductive Medicine \& the Society for Assisted Reproductive Technology, 2018; Harton et al., 2013; Homer, 2019). A significant reduction in the miscarriage rate from $26 \%$ to $10 \%$ in women younger than 35 years of age and from $39 \%$ to $13 \%$ in those over 35 years was reported in a study by Hodes-Wertz et al. (2012). Additionally, a multicenter study in patients over 35 years found miscarriage rates of $7 \%$ and $14 \%$ in cases with and without PGT-A, respectively (Verpoest et al., 2018).

The reliability and success of PGT-A depend not only on the proper functioning of a reproductive clinic but also on the expertise of the laboratory personnel and suitable sample processing and analysis. Among the study's limitations are the impossibility of controlling some variables due to the retrospective nature of the study; besides, PGT-A was not randomly indicated because, in some cases, it was chosen by the patients.

\section{CONCLUSIONS}

PGT-A is a screening approach for embryos, being frequently used in the area of reproductive medicine. Over time, PGT-A has been indicated for some specific groups: patients over 40 years of age, recurrent pregnancy loss, recurrent implantation failure, and history of inherited genetic abnormalities. In this study, the aneuploidies most frequently found in embryos were complex chromosomal abnormalities followed by mosaicism and double aneuploidies. Besides, a positive correlation was found between maternal age and aneuploidy rate. It is noteworthy that the miscarriage rate found was $0 \%$ upon transfer of euploid embryos, previously identified by PGT-A.

\section{Financial support}

This study was funded by the Instituto de Fertilidad Humana - Inser Bogotá.

\section{CONFLICT OF INTEREST}

The authors declare no conflict of interest.

\section{Corresponding author:}

Germán David Ospina Idárraga, Instituto de Fertilidad Humana - Inser Bogotá Bogotá, Colombia.

E-mail: gospina@inser.com.co

\section{REFERENCES}

Achache $H$, Revel A. Endometrial receptivity markers, the journey to successful embryo implantation. Hum Reprod Update. 2006;12:731-46. PMID: 16982667 DOI: 10.1093/ humupd/dml004

Álvarez Sedó C. Estudio Genético Pre-Implantatorio para aneuploidías (PGT-A): Una revisión crítica actualizada. Reproducción. 2018;33:21-43. 
ASEBIR - Asociación para el Estudio de la Biologia de Reproduccíon. Criterios ASEBIR de Valoración Morfológica de Oocitos, Embriones Tempranos y Blastocistos Humanos. 3a ed. Madrid: Góbalo, Agencia Creativa Digital; 2015.

Ata B, Kaplan B, Danzer H, Glassner M, Opsahl M, Tan SL, Munné S. Array CGH analysis shows that aneuploidy is not related to the number of embryos generated. Reprod Biomed Online. 2012;24:614-20. PMID: 22503277 DOI: 10.1016/j.rbmo.2012.02.009

Blockeel C, Schutyser V, De Vos A, Verpoest W, De Vos M, Staessen C, Haentjens P, Van der Elst J, Devroey P. Prospectively randomized controlled trial of PGS in IVF/ICSI patients with poor implantation. Reprod Biomed Online. 2008;17:84854. PMID: 19079970 DOI: 10.1016/S1472-6483(10)60414-2

Chang J, Boulet SL, Jeng G, Flowers L, Kissin DM. Outcomes of in vitro fertilization with preimplantation genetic diagnosis: an analysis of the United States Assisted Reproductive Technology Surveillance Data, 2011-2012. Fertil Steril. 2016;105:394-400. PMID: 26551441 DOI: 10.1016/j.fertnstert.2015.10.018

Chen M, Wei S, Hu J, Quan S. Can Comprehensive Chromosome Screening Technology Improve IVF/ICSI Outcomes? A Meta-Analysis. PLoS One. 2015;10:e0140779. PMID: 26470028 DOI: 10.1371/journal.pone.0140779

Coates A, Kung A, Mounts E, Hesla J, Bankowski B, Barbieri E, Ata B, Cohen J, Munné S. Optimal euploid embryo transfer strategy, fresh versus frozen, after preimplantation genetic screening with next generation sequencing: a randomized controlled trial. Fertil Steril. 2017;107:723-30.e3. PMID: 28139240 DOI: 10.1016/j.fertnstert.2016.12.022

Ebner T, Moser M, Sommergruber M, Tews G. Selection based on morphological assessment of oocytes and embryos at different stages of preimplantation development: a review. Hum Reprod Update. 2003;9:251-62. PMID: 12859046 DOI: $10.1093 /$ humupd/dmg021

ESHRE - European Society of Human Reproduction and Embryology. Recurrent Pregnancy Loss. Guideline of the European Society of Human Reproduction and Embryology. Strombeek-Bever: ESHRE; 2017. Available at: https:// www.eshre.eu/Guidelines-and-Legal/Guidelines/Recurrent-pregnancy-loss.aspx

Fiorentino $F$, Bono $S$, Biricik A, Nuccitelli A, Cotroneo $E$, Cottone G, Kokocinski F, Michel CE, Minasi MG, Greco E. Application of next-generation sequencing technology for comprehensive aneuploidy screening of blastocysts in clinical preimplantation genetic screening cycles. Hum Reprod. 2014;29:2802-13. PMID: 25336713 DOI: 10.1093/hum$\mathrm{rep} / \mathrm{deu} 277$

Forman EJ, Hong KH, Ferry KM, Tao X, Taylor D, Levy B, Treff NR, Scott RT Jr. In vitro fertilization with single euploid blastocyst transfer: a randomized controlled trial. Fertil Steril. 2013;100:100-7.e1. PMID: 23548942 DOI: 10.1016/j.fertnstert.2013.02.056

Franasiak JM, Forman EJ, Hong KH, Werner MD, Upham KM, Treff NR, Scott RT Jr. The nature of aneuploidy with increasing age of the female partner: a review of 15,169 consecutive trophectoderm biopsies evaluated with comprehensive chromosomal screening. Fertil Steril. 2014;101:656-63.e1. PMID: 24355045 DOI: 10.1016/j.fertnstert.2013.11.004
Gardner DK, Vella P, Lane M, Wagley L, Schlenker T, Schoolcraft WB. Culture and transfer of human blastocysts increases implantation rates and reduces the need for multiple embryo transfers. Fertil Steril. 1998;69:84-8. PMID: 9457939 DOI: $10.1016 / S 0015-0282(97) 00438-X$

Greco E, Bono S, Ruberti A, Lobascio AM, Greco P, Biricik A, Spizzichino L, Greco A, Tesarik J, Minasi MG, Fiorentino $F$. Comparative genomic hybridization selection of blastocysts for repeated implantation failure treatment: a pilot study. Biomed Res Int. 2014;2014:457913. PMID: 24779011 DOI: $10.1155 / 2014 / 457913$

Haddad G, Deng M, Wang CT, Witz C, Williams D, Griffith J, Skorupski J, Gill J, Wang WH. Assessment of aneuploidy formation in human blastocysts resulting from donated eggs and the necessity of the embryos for aneuploidy screening. J Assist Reprod Genet. 2015;32:999-1006. PMID: 25956263 DOI: 10.1007/s10815-015-0492-4

Harper J, Coonen E, De Rycke M, Fiorentino F, Geraedts J, Goossens V, Harton G, Moutou C, Pehlivan Budak T, Renwick P, Sengupta S, Traeger-Synodinos J, Vesela K. What next for preimplantation genetic screening (PGS)? A position statement from the ESHRE PGD Consortium Steering Committee. Hum Reprod. 2010;25:821-3. PMID: 20124394 DOI: 10.1093/humrep/dep476

Harper JC, Wilton L, Traeger-Synodinos J, Goossens V, Moutou C, SenGupta SB, Pehlivan Budak T, Renwick P, De Rycke M, Geraedts JP, Harton G. The ESHRE PGD Consortium: 10 years of data collection. Hum Reprod Update. 2012;18:234-47. PMID: 22343781 DOI: 10.1093/humupd/dmr052

Harton GL, Munné S, Surrey M, Grifo J, Kaplan B, McCulloh DH, Griffin DK, Wells D; PGD Practitioners Group. Diminished effect of maternal age on implantation after preimplantation genetic diagnosis with array comparative genomic hybridization. Fertil Steril. 2013;100:1695-703. PMID: 24034939 DOI: 10.1016/j.fertnstert.2013.07.2002

Hodes-Wertz B, Grifo J, Ghadir S, Kaplan B, Laskin CA, Glassner $M$, Munné $S$. Idiopathic recurrent miscarriage is caused mostly by aneuploid embryos. Fertil Steril. 2012;98:675-80. PMID: 22683012 DOI: 10.1016/j.fertnstert.2012.05.025

Homer HA. Preimplantation genetic testing for aneuploidy (PGT-A): The biology, the technology and the clinical outcomes. Aust N Z J Obstet Gynaecol. 2019;59:317-24. PMID: 30811595 DOI: 10.1111/ajo.12960

Kang HJ, Melnick AP, Stewart JD, Xu K, Rosenwaks Z. Preimplantation genetic screening: who benefits? Fertil Steril. 2016;106:597-602. PMID: 27143516 DOI: 10.1016/j. fertnstert.2016.04.027

Kung A, Munné S, Bankowski B, Coates A, Wells D. Validation of next-generation sequencing for comprehensive chromosome screening of embryos. Reprod Biomed Online. 2015;31:760-9. PMID: 26520420 DOI: 10.1016/j. rbmo.2015.09.002

Magli MC, Gianaroli L, Ferraretti AP, Gordts S, Fredericks V, Crippa A. Paternal contribution to aneuploidy in preimplantation embryos. Reprod Biomed Online. 2009;18:536-42. PMID: 19400996 DOI: 10.1016/ S1472-6483(10)60131-9 
Mastenbroek S, Twisk M, van der Veen F, Repping S. Preimplantation genetic screening: a systematic review and meta-analysis of RCTs. Hum Reprod Update. 2011;17:45466. PMID: 21531751 DOI: 10.1093/humupd/dmr003

Milán M, Cobo AC, Rodrigo L, Mateu $E$, Mercader A, Buendía $P$, Peinado $V$, Delgado $A$, Mir $P$, Simón $C$, Remohí J, Pellicer A, Rubio C. Redefining advanced maternal age as an indication for preimplantation genetic screening. Reprod Biomed Online. 2010;21:649-57. PMID: 20864410 DOI: $10.1016 /$ j.rbmo.2010.06.020

Munné S, Grifo J, Wells D. Mosaicism: "survival of the fittest" versus "no embryo left behind". Fertil Steril. 2016;105:1146-9. PMID: 26827669 DOI: 10.1016/j.fertnstert.2016.01.016

Palmerola KL, Vitez SF, Amrane S, Fischer CP, Forman EJ. Minimizing mosaicism: assessing the impact of fertilization method on rate of mosaicism after next-generation sequencing (NGS) preimplantation genetic testing for aneuploidy (PGT-A). J Assist Reprod Genet. 2019;36:153-7. PMID: 30362056 DOI: 10.1007/s10815-018-1347-6

Practice Committees of the American Society for Reproductive Medicine and the Society for Assisted Reproductive Technology. Electronic address: ASRM@asrm.org; Practice Committees of the American Society for Reproductive Medicine and the Society for Assisted Reproductive Technology. The use of preimplantation genetic testing for aneuploidy (PGT-A): a committee opinion. Fertil Steril. 2018;109:429-36. PMID: 29566854 DOI: $10.1016 / j$.fertnstert.2018.01.002

Revelli A, Biasoni V, Gennarelli G, Canosa S, Dalmasso P, Benedetto $C$. IVF results in patients with very low serum AMH are significantly affected by chronological age. J Assist Reprod Genet. 2016;33:603-9. PMID: 26888025 DOI: $10.1007 / \mathrm{s} 10815-016-0675-7$

Rodrigo L, Mateu E, Mercader A, Cobo AC, Peinado V, Milán M, Al-Asmar N, Campos-Galindo I, García-Herrero S, Mir P, Simón C, Rubio C. New tools for embryo selection: comprehensive chromosome screening by array comparative genomic hybridization. Biomed Res Int. 2014;2014:517125. PMID: 24877108 DOI: $10.1155 / 2014 / 517125$

Rubio C, Bellver J, Rodrigo L, Bosch E, Mercader A, Vidal C, De los Santos MJ, Giles J, Labarta E, Domingo J, Crespo J, Remohí J, Pellicer A, Simón C. Preimplantation genetic screening using fluorescence in situ hybridization in patients with repetitive implantation failure and advanced maternal age: two randomized trials. Fertil Steril. 2013a;99:1400-7. PMID: 23260857 DOI: 10.1016/j.fertnstert.2012.11.041

Rubio C, Rodrigo L, Mir P, Mateu E, Peinado V, Milán M, Al-Asmar N, Campos-Galindo I, Garcia S, Simón C. Use of array comparative genomic hybridization (array-CGH) for embryo assessment: clinical results. Fertil Steril. 2013b;99:1044-8. PMID: 23394777 DOI: 10.1016/j.fertnstert.2013.01.094

Sánchez-Usabiaga R, Ramírez-Rivera EG, Durand-Montaño C. Frequency of segmental aneuploidies in trophectoderm biopsies during an IVF cycle and its relationship with maternal age. Ginecol Obstet Mex. 2017;85:510-8.
Schoolcraft WB, Katz-Jaffe MG, Stevens J, Rawlins M, Munne S. Preimplantation aneuploidy testing for infertile patients of advanced maternal age: a randomized prospective trial. Fertil Steril. 2009;92:157-62. PMID: 18692827 DOI: $10.1016 /$ j.fertnstert.2008.05.029

Scott RT Jr, Upham KM, Forman EJ, Hong KH, Scott KL, Taylor D, Tao X, Treff NR. Blastocyst biopsy with comprehensive chromosome screening and fresh embryo transfer significantly increases in vitro fertilization implantation and delivery rates: a randomized controlled trial. Fertil Steril. 2013;100:697-703. PMID: 23731996 DOI: 10.1016/j. fertnstert.2013.04.035

Shinawi M, Cheung SW. The array CGH and its clinical applications. Drug Discov Today. 2008;13:760-70. PMID: 18617013 DOI: $10.1016 /$ j.drudis. 2008.06 .007

Simon AL, Kiehl M, Fischer E, Proctor JG, Bush MR, Givens C, Rabinowitz M, Demko ZP. Pregnancy outcomes from more than 1,800 in vitro fertilization cycles with the use of 24-chromosome single-nucleotide polymorphism-based preimplantation genetic testing for aneuploidy. Fertil Steril. 2018;110:113-21. PMID: 29908770 DOI: $10.1016 / j$.fertnstert.2018.03.026

Simpson JL. Preimplantation genetic diagnosis at 20 years. Prenat Diagn. 2010;30:682-95. PMID: 20572111 DOI: $10.1002 / p d .2552$

Verpoest W, Staessen C, Bossuyt PM, Goossens V, Altares$\mathrm{cu}$ G, Bonduelle M, Devesa M, Eldar-Geva T, Gianaroli L, Griesinger G, Kakourou G, Kokkali G, Liebenthron J, Magli MC, Parriego M, Schmutzler AG, Tobler M, van der Ven K, Geraedts J, Sermon K. Preimplantation genetic testing for aneuploidy by microarray analysis of polar bodies in advanced maternal age: a randomized clinical trial. Hum Reprod. 2018;33:1767-76. PMID: 30085138 DOI: 10.1093/ humrep/dey 262

Vitez SF, Forman EJ, Williams Z. Preimplantation genetic diagnosis in early pregnancy loss. Semin Perinatol. 2019;43:116-20. PMID: 30655022 DOI: 10.1053/j.semperi.2018.12.009

Wilton L. Preimplantation genetic diagnosis for aneuploidy screening in early human embryos: a review. Prenat Diagn. 2002;22:512-8. PMID: 12116318 DOI: 10.1002/ pd. 388

Yang Z, Liu J, Collins GS, Salem SA, Liu X, Lyle SS, Peck AC, Sills ES, Salem RD. Selection of single blastocysts for fresh transfer via standard morphology assessment alone and with array CGH for good prognosis IVF patients: results from a randomized pilot study. Mol Cytogenet. 2012;5:24. PMID: 22551456 DOI: $10.1186 / 1755-8166-5-24$

Zegers-Hochschild F, Crosby JA, Musri C, de Souza MDCB, Martinez AG, Silva AA, Mojarra JM, Masoli D, Posada N; Latin American Network of Assisted Reproduction. Assisted reproductive technology in Latin America: the Latin American Registry, 2017. Reprod Biomed Online. 2020a;41:44-54. PMID: 32417198 DOI: $10.1016 /$ j.rbmo.2020.02.004 